\title{
Transforming the enterprise architecture through personnel design
}

\author{
Igor Petrov ${ }^{1 *}$, Lev Bulychev ${ }^{1}$, Natalia Bushueva ${ }^{2}$, and Aleksandr Zheltenkov ${ }^{3}$ \\ ${ }^{1}$ Vyatka State University, 36, Moskovskaya str., Kirov, Russia \\ ${ }^{2}$ University named after S.Yu. Witte, 2nd Kozhukhovsky passage, 12, bld.1, Moscow \\ ${ }^{3}$ Moscow Region State University, 105005, Radio str, 10A, Moscow, Russia
}

\begin{abstract}
Changes in the external environment, market and technology require adaptability and flexibility of organizations. It is realized through system monitoring and continuous business transformation and requires changes in the system of goals and indicators, policies, business processes, organizational structure, and IT solutions. Such transformations need systemic coordination in several functional areas: strategic management, performance management, business process management, organizational design, information systems design, personnel management, knowledge management, etc. The article describes possibilities of transforming the enterprise architecture through personnel design. This method is not studied well enough as the human factor is mostly unpredictable, but it is the basis of all transformations. The developed methodology was tested at the department of Vyatka State University. As a result, the authors have identified reasons for the low efficiency of certain types of activities and described necessary intertypes for strengthening positions. The research states that intertype analysis allows to simulate the microclimate in a department or organization. Moreover, understanding intertype relationships helps to manage implicit knowledge and communication between employees, which is very important according to Kaizen.
\end{abstract}

\section{Introduction}

Currently, the company needs to respond quickly to changes in the external environment, market and technology, to be flexible and meet different internal and external standards. Adaptability and flexibility of the organization is implemented through monitoring and continuous business transformation. It requires changes in the system of goals and indicators, policies, business processes, organizational structure and IT solutions. Such transformations need system coordination in several functional areas: strategic management, performance management, business process management, organizational design, information systems design, personnel management, knowledge management, etc. Most companies make efforts to transform their activities through local changes. However, obtaining a positive local effect does not always lead to a positive result, since it is difficult

\footnotetext{
* Corresponding author: soft.rosko@mail.ru
} 
to see an adequate picture of particular situations without understanding and analyzing the situation in general.

The term "enterprise architecture" (or "corporate architecture") can provide a holistic understanding of a company's structure. The term "enterprise architecture" (EA) is used to denote a certain management object that provides a common view and interconnection of parts into a single whole in business. Also it can denote a discipline arising on the basis of this object $[1,2]$. The enterprise architecture methodologies make it possible to objectify and specify concepts which form the basis of various organization theories and managerial approaches [3-5]. It happens, for example, by applying appropriate modeling languages, such as Archimate [6], complex methods for creating and using EA models, such as TOGAF, reference models [7] such as the reference model of operations in SCOR supply chains [8], etc. A significant role in EA is given to the accumulation and reuse of knowledge, which is recorded in the form of reference books, templates and reference models [9-11].

Currently, the use of EA in developing information systems and IT management is considered in details [12-15]. However, the role of EA in the management is not studied and presented in a limited number of researches [16].

The main problem of large companies is the lack of correct information about the existing IT support of the business and the strategy for its further development. A paradoxical situation is in the fact that IT increases the efficiency of enterprise management, but at the same time their development is chaotic. We need a tool that ensures the interconnection of strategic goals and objectives of the enterprise, business processes and technologies. We need to develop enterprise architecture. Enterprise architecture is a tool for a systematic description of enterprise functioning and principles of organization development.

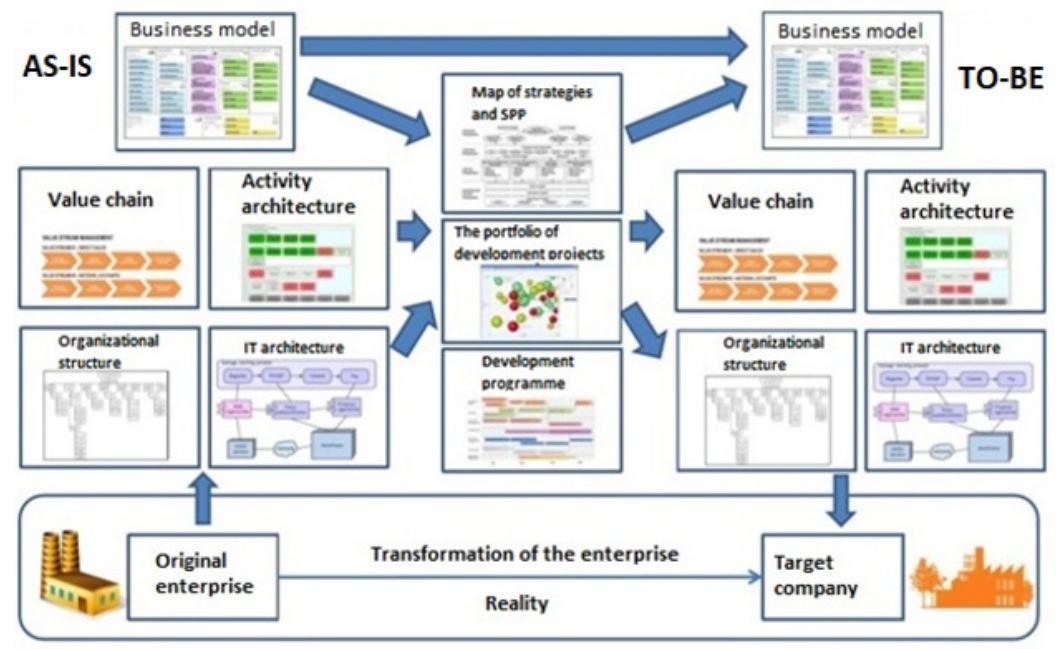

Fig. 1. Architectural approach to enterprise transformation.

All architectural changes are based on people, participants of the transformation and their competence. It is necessary to underline that the issue of managing staff abilities and relationship management remains outside. This approach to transformation leads to increased risks, since relations between employees are not taken into account when organizing project teams for architectural changes. As it is known from the research [17], half of the time of the project needs for settling team relations. Therefore, if a year is given for the project, half a year needs for making relations in the project team (Fig. 2). 


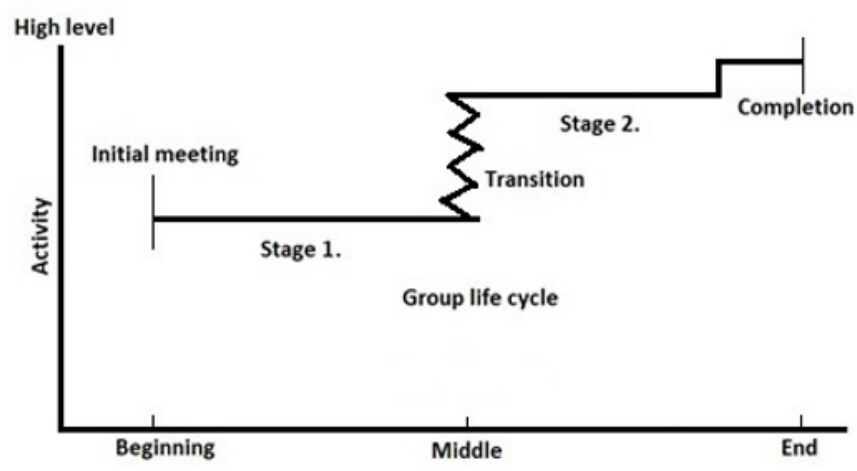

Fig. 2. The punctuated equilibrium model of group development [4].

The same can be said about the restructuring of the enterprise structure. We break the existing relations when 'new' employees come, 'old' employees go away, or when they change their roles. It leads to increased risks in the area of work and relationships.

\section{Methods}

To solve all these problems, we propose a personnel design method. It is based on psychoinformation technologies that allow to predict abilities of a team and interpersonal relationships.

The use of psycho-information technologies gives opportunities for matching the abilities of personnel and activities, with the possibility of adjusting relations, changing the structure of the project team and / or a department while keeping people's functions.

The functions are fixed according to the typing results. In this case, preliminary typing of employees (Table 2) and functions (work) of the department (Table 1) occurs. After that, it becomes clear which functions (work) correspond to a particular employee. In this case, knowing the strengths and weaknesses of the employee, you can re-assign functions. It is possible to remove functions if the employee is weak in doing them and give them to the employee who is strong. You can increase efficiency by rotating the function within a department or project team, while maintaining employee satisfaction. If he works using his strong functions, he gets less tired.

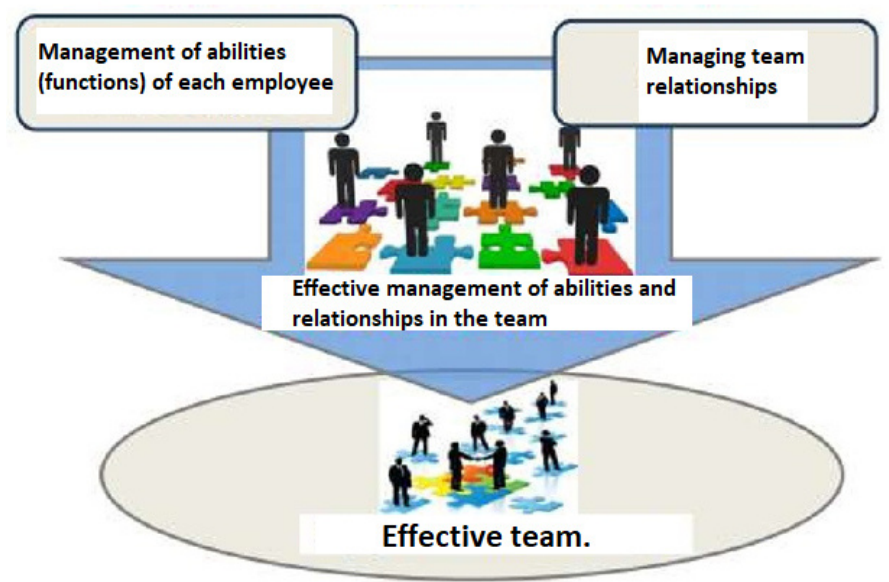

Fig. 3. Talent management and team relationships. 
A typological analysis of functions (works) makes it possible to match a person's abilities and job responsibilities. And analysis of mutual relations gives the possibility to model relationships in a team.

Table 1. Typological analysis of functions (works).

\begin{tabular}{|c|c|c|c|c|c|c|c|c|}
\hline \multirow{2}{*}{$\begin{array}{l}\text { Types of work / function } \\
\text { Information aspect }\end{array}$} & \multicolumn{8}{|c|}{ Information aspect } \\
\hline & 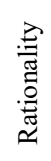 & 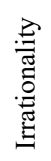 & 鄫 & 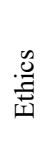 & : & $\begin{array}{l}\overrightarrow{0} \\
0 \\
\bar{D} \\
\end{array}$ & 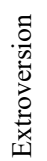 & 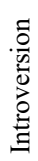 \\
\hline $\begin{array}{l}\text { 1. Collection and analysis of } \\
\text { information on the construction } \\
\text { market }\end{array}$ & + & & + & & + & & & \\
\hline 2. Finding customers & & & & + & + & & + & \\
\hline 3. Negotiations with clients & + & & & + & & + & & \\
\hline $\begin{array}{l}\text { 4. Execution and conclusion of } \\
\text { contracts }\end{array}$ & + & & + & & & + & & \\
\hline$\ldots$ & & & & & & & & \\
\hline TOTAL & & & & & & & & \\
\hline
\end{tabular}

Using the typological analysis of works (Table 1) and the typological map of employees (Table 2), it is possible to match a person's ability with the required functions.

Table 2. Typological map of employees.

\begin{tabular}{|c|c|c|}
\hline Name & Position & Social Type \\
\hline Sidorov & Director & Administrator \\
\hline Petrov & Head of sales & Politician \\
\hline Ivanov & Sales Manager & Analyst \\
\hline$\ldots$ & $\ldots$ & $\ldots$ \\
\hline
\end{tabular}

Table 3 presents the analysis of the intertype relationships of employees. The interpretation of values and the assessment of intertype relationships are examined in detail in many socionics works [18-22]. Intertype communications allow to evaluate the quality of relations in the team and the relationship between any two people in a department or project.

\section{Results}

In the generalized form, the work of personnel design means modeling functions and relationships, choosing the optimal staff for projects of transformation, optimization and formation of departments (Figure 4). 


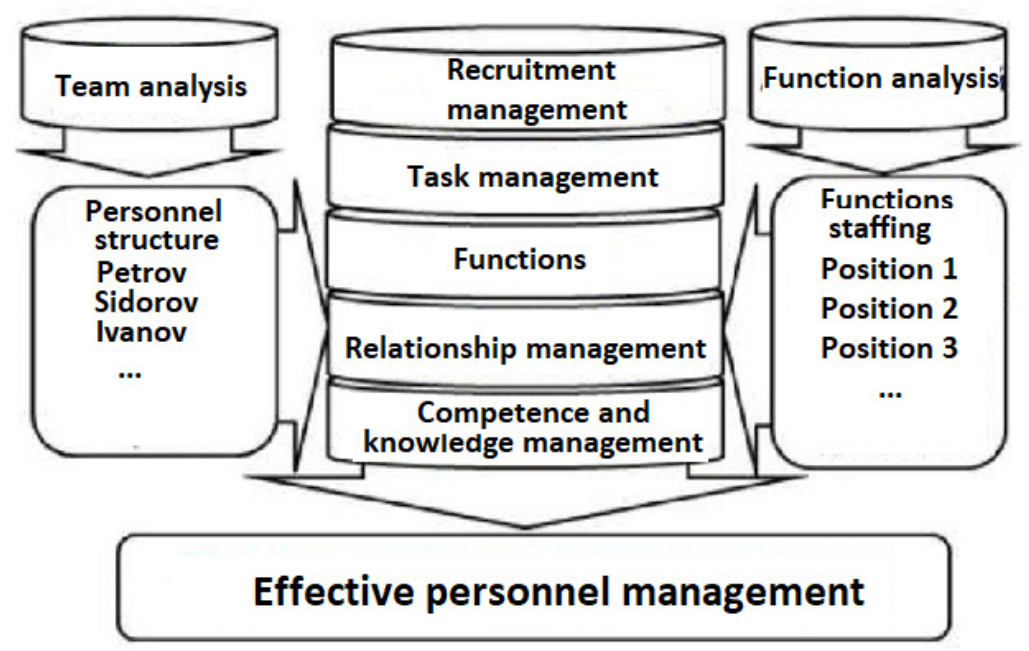

Fig.4. Personnel management in the organization.

Thus, the use of "personnel design" is possible as an element of complementing transformational changes of an enterprise and as an element of personnel management of both the whole enterprise and an individual department or project. This approach allows to collect highly effective teams, minimizing conflicts and optimizing the microclimate.

\section{Discussion}

To test the developed methodology, the authors have investigated personnel of one department at Vyatka State University. 3 types of activities were selected as guidelines: research, educational and contractual (provision of services to outside organizations). Detailed investigaton of these activities has shown that:

- $\quad$ intuitive logics strengthened by sensory ethics is most successfully used for scientific research;

- $\quad$ sensory logics strengthened by intuitive ethics is best used for contract activities;

- $\quad$ sensory ethics strengthened by intuitive logics is best used for educational work.

This approach allows to consider the full range of tasks which need to be solved.

According to test results, the personnel of the department consists mainly of sensory ethics and intuitive ethics. The intertype distribution diagram of the department is presented in Figure 5.

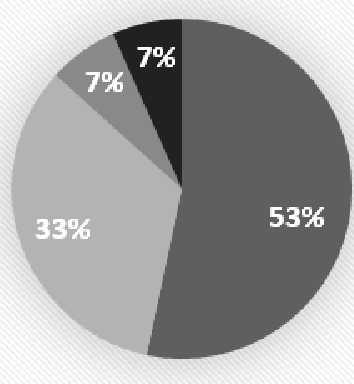

- Sensory Ethics

Intuitive Ethics

- Intuitive Logic

- Sensory Logic

Fig.5. Personnel management in the organization. 
Thus, the team is effectively focused only on the educational process, which is implemented effectively due to the dominant ethics. The weakness of the team is the presence of only one intuitive and sensory logic. Therefore, research and contract activities are not realized in this team.

As a result of the research, the head of the department has defined contract activity as a priority. So, it was decided to restructure the staff by attracting three part-time employees to work with third-party organizations.

Obviously, the third type of activity is not present at the department, but the department mainly implements applied programs. Therefore, at the moment, the aim of the department is to increase the efficiency of the first two areas.

\section{Conclusion}

The method of personnel design harmoniously complements the enterprise architectural transformation. Thanks to it, it is possible to predict human factor in management, make it more transparent and understandable. This approach gives opportunities to improve the ability management of each employee and match functional responsibilities with their abilities. At the same time, it is possible to optimize the microclimate in a department or organization by modeling intertype relationships. The intertype analysis of relations allows to use rotations and changes in the personnel structure to harmonize relations in the team. In addition, understanding intertype relationships becomes the basis for managing implicit knowledge and communication between employees, which is very important according to Kaizen and the spiral of managing explicit and implicit knowledge in an organization. The method of personnel design can be used as an essential element of complementing knowledge management system in an organization. It gives new possibilities in the formation and creation of explicit knowledge, taking into account the information exchange between employees.

\section{References}

1. M. Lankhorst, Enterprise Architecture at Work. Modelling, Communication and Analysis. (3rd ed. Springer-Verlag Berlin Heidelberg, 2013).

2. M. Op't Land, E. Proper E, M.Waage, J. Cloo, C.Steghuis Enterprise Architecture: Creating Value by Informed Governance. (Springer-Verlag Berlin Heidelberg, 2009).

3. I. Klemina, Theory of Organization. (Saint-Petersburg: High School of management, 2009).

4. B.Z. Milner, Theory of Organization.( Moscow: Infra-M, 2012).

5. V.L. Tambovtsev, The strategic theory of the company: state and possible development. Russian Management Journal, 8(1), Pp.5-40 (2010)

6. M. M. Lankhorst, H.A. Proper, H. Jonkers, The anatomy of the archimate language. International Journal of Information System Modeling and Design, 1(1), Pp.1-32, (2010).

7. P. Fettke, P.Loos, Reference Modeling for Business Systems Analysis (IGI Global: Hershey, 2006).

8. S. H. Huan, S. K. Sheoran, G.Wan, A review and analysis of supply chain operations reference (SCOR) model. Supply Chain Management, 9(1), Pp.23-29, (2004). 
9. D.V. Kudryavtsev, M.Yu Arzumanyan, Enterprise architecture: transition from IT infrastructure design to business transformation. Russian Management Journal, 2(15), Pp.193-224 (2017).

10. A.V. Bataev, A.A. Gorovoy, A.B. Mottaeva, Proceedings of the 32nd International Business Information Management Association Conference, IBIMA 2018 - Vision 2020: Sustainable Economic, pp. 88-101(2018)

11. L.Yu Grigoriev, D.V. Kudryavtsev, Systematic approach and optimization of organizations // Methods of quality management, 9, Pp.4-8 (2017)

12. A. Danilin, A. Slyusarenko, Enterprise architecture. "Yin" and "Yang" enterprise information technology (Moscow: Internet University of Information Technology, 2005).

13. A. Danilin, A. Slyusarenko, Enterprise architecture (INTUIT: National open university, 2019).

14. E.Z. Zinder, The modern architectural approach and its practical application in the framework of old and new design standards. Practice of the architectural approach: concepts, standards, terminology, models and their application, 4(7), (2008).

15. G.N. Kalyanov, Methods and tools for modeling enterprise architecture. Problems of management theory and practice, 5, Pp.79-91(2006)

16. L.N. Nikolova, D. G. Rodionov, M.A. Bahauovna, International Journal of Economics and Financial, 6(2), 246-252 (2016)

17. Erik W. Larson, Clifford F. Gray, Project Management The Managerial Process, (5th Edition, The McGraw-Hill/Irwin).

18. V.V. Gulenko, Management of a well-coordinated team: Socionics for managers, (Moscow, AST, 2005)

19. G. Dyakova, S. Izmaylova, A. Mottaeva, E. Karanina, IOP Conf. Series: Earth and Environmental Science, 90, 012218 (2017) doi :10.1088/1755-1315/90/1/012218

20. G. Fink, W. Mayrhofer, Cross-cultural competence and management - setting the stage. European Journal of Cross-Cultural Competence and Management, 1 (1), (2009).

21. O.Kroeger, J.M Thuesen, Type talk at work: how 16 personality types determine your success on the job (Dell Publishing. 1993).

22. Jean M. Kummerow, Nancy J. Barger, Linda K. Kirby, Work Types ( Grand Central Publishing; 1 edition, 1997). 